(2) Open Access Full Text Article

ORIGINAL RESEARCH

\title{
Improvement of $\mathrm{HbAlc}$ in Patients with Type 2 Diabetes Mellitus and Rheumatoid Arthritis Treated with bDMARDs
}

\author{
Alfredomaria Lurati $\mathbb{B}^{1}$ \\ Antonella Laria' \\ Daniela Mazzocchi' \\ Katia Angela Re' \\ Maria Grazia Marrazza' \\ Paola Maria Faggioli ${ }^{2}$ \\ Antonino Mazzone ${ }^{2}$
}

'Rheumatology Unit, Fornaroli Hospital Magenta Italy, Milan, Italy; ${ }^{2}$ Internal Medicine Unit, Legnano Hospital, Milan, Italy
Correspondence: Alfredomaria Lurati Rheumatology Unit Fornaroli Hospital Magenta Italy, Via Donatore Sangue 50, Milan, 22100, Italy

Email alfredomaria.lurati@asst-ovestmi.it
Objective: The aim of our study was to evaluate the possible role of biological treatments for rheumatoid arthritis (RA) in improving the glycemic profile in patients affected not only by RA but also by type 2 diabetes mellitus (2TDM).

Methods: An observational retrospective study was conducted using data from patients referred to our Rheumatology Unit. Patients with active RA despite standard DMARDs therapy and concomitant 2TDM were selected into one of five exposure groups to first-line bDMARDs (adalimumab, golimumab, etanercept, tocilizumab, sarilumab) and observed for the outcome of CRP, ESR, DAS28CRP and glycated hemoglobin (HbA1c) variations.

Results: After the start of treatment, there was a significant reduction in the values of acute phase reactants ESR and CRP ( $p<0.01)$, DAS28-CRP $(p<0.01)$ and HbA1C $(p<0.05)$, in the absence of any confounding factors such as a reduction in BMI or a change in steroid doses. There was no statistically significant difference between the various treatments. Anti-IL6 drugs appear to be associated with a slightly greater reduction in $\mathrm{HbAlc}$ values, bordering on statistical significance $(\mathrm{p}=0.047)$.

Conclusion: Initiation of a bDMARD appears to be associated with an improvement in concomitant $2 \mathrm{TDM}$ in patients with active RA, which, in the first hypothesis, is linked with a reduction of the inflammatory milieu.

Keywords: diabetes mellitus, rheumatoid arthritis, bDMARDs

\section{Background}

In the literature there are various studies that suggest that patients with rheumatoid arthritis (RA) have a higher risk of developing diabetes (DM). It's also well known that insulin resistance is an independent risk factor for cardiovascular diseases (CVD). ${ }^{1-5}$

Moreover, patients with rheumatoid arthritis (RA) have an increased cardiovascular risk, estimated to be about 50\% greater when compared to the general population and a correlation between insulin resistance, type II diabetes mellitus (2TDM) and RA is described in the literature.

The pro-inflammatory milieu that characterizes active RA (for example, high levels of cytokines such as IL1, IL6 and TNFalpha) may have a relationship with altered insulin production and therefore insulin resistance, as described by Esser and $\mathrm{Wu}$, among others. ${ }^{6,7}$ Although the potential link between pro-inflammatory milieu and insulin resistance is intriguing, to date few studies have assessed a possible relationship between disease activity (eg using a composite index such as DAS28-CRP or SDAI) and a DM marker such as as glycated haemoglobin., ${ }^{8,9}$ 
Recently, the therapeutic arsenal against RA has been enriched by various agents such as antiTNF (etanercept, adalimumab, golimumab, infliximab), anti CD20 (rituximab), anti IL6 (tocilizumab, sarilumab) and fusion protein with CTLA4Immunoglobulin (abatacept), which is designed to modulate the $\mathrm{T}$ cell co-stimulatory signal mediated through the CD28CD80/86 pathway (bDMARDs).

In this study, we test the possible role of some bDMARDs in improving a concomitant 2TDM in patients with RA, evaluating periodically over 6 months the HbA1c values in parallel with DAS28-CRP, based on the hypothesis that a reduction of disease activity can lead to a better balance of glucidic metabolism.

\section{Methods}

\section{Study Design}

This study has been designed as an observational retrospective study. Clinical data were collected from patients with RA and 2TDM who started a first line of therapy with bDMARDs between October 2019 and December 2020.

Inclusion criteria were predefined as follows: moderate to severe disease activity as defined by DAS28-CRP despite treatment with standard disease-modifying anti-rheumatic drugs (DMARDs), stable treatment with methotrexate or other DMARDs. Concomitant 2TDM was treated with a stable dose of an insulin-sensitizing agent, such as metformin. Exclusion criteria were: infectious, neoplastic diseases, recent changes in dose of oral steroids and a daily steroid dose higher than $10 \mathrm{mg} /$ die of prednisone.

Given the observational design of the study, patients were eligible for treatment with biotechnological drugs (bDMARDs) if they were non-responders to standard DMARDS. Baseline data comprised anthropometric measurements (height, weight and body mass index), disease activity assessment based on DAS28-CRP calculation and lab test evaluations of ESR, CRP, glycemia and glycated hemoglobin. Patients were subsequently treated with a bDMARD according to the established procedures. After 3 and 6 months of treatment, patients were reassessed with the same schedule. The choice of bDMARD was made by a rheumatology expert in the use of these drugs, in accordance with the peculiar characteristics of the individual patient. This study was conducted in accordance with the ethics principles of the Declaration of Helsinki and was approved by the local research ethics committees.

\section{Statistical Analysis}

Data are expressed as mean standard deviation (SD), median (25th-75th percentile) or number (percentage), as appropriate. Continuous variables that were not normally distributed were $\ln$-transformed before analysis. Paired samples student's $t$-test or ANOVA have been used, where appropriate, to compare means. The Pearson product-moment correlation coefficient was used to evaluate correlations between variables.

A p-value $<0.05$ was considered statistically significant. All tests were two-tailed. The Statistical Package for Social Sciences (SPSS for Windows, version 20.0, SPSS Inc., Chicago, IL) was used for all analyses.

\section{Clinical Outcomes}

Data relating to 67 patients with active RA (DAS28-CRP >3.2) despite treatment with MTX and T2DM were collected from 3 months before (t-3) the start of bDMARD (T0) treatment up to 6 months after, every 3 months (T3, T6). Fourteen were treated with adalimumab, 23 with etanercept, 15 with golimumab, 6 with sarilumab and 9 with tocilizumab. Anthropometric data are shown in Table 1.

\section{Results}

DAS28-CRP/HbA1c mean values $( \pm \mathrm{SD})$ at $\mathrm{T}-3$ and $\mathrm{T} 0$ were $5.15( \pm 0.37) / 46.7( \pm 6.6) \mathrm{mmol} / \mathrm{l}$ and $5.25( \pm 0.39) /$ $48.9( \pm 7.8)$, respectively. After the therapy with bDMARDs was started, a significant lowering in ESR, CRP, DAS28-CRP and HbA1c values was observed (Figures 1 and 2 show DAS28-CRP and HbA1c) at 3 months and 6 months $(\mathrm{p}<0.01)$. The ANOVA test did not showe a significant difference between the bDMARD treatments; rather, it showed only a statistical trend towards treatment with tocilizumab and sarilumab vs anti TNF ( $p=0.047)$. No significant variation in anthropometric values was observed $(\mathrm{p}>0.5)$ (Table 2$)$.

Table I Demographic Data of the Whole Population

\begin{tabular}{|c|c|}
\hline & Whole Population $(\mathrm{N}=67)$ \\
\hline Males n (\%) & $28(41.7 \%)$ \\
\hline Age, years $( \pm S D)$ & $57.8 \pm 4.5$ \\
\hline RA duration, years & $2.8 \pm 1.8$ \\
\hline Weight, kg ( $\pm S D)$ & $84 \pm 8.5$ \\
\hline Height, $m( \pm S D)$ & $1.69 \pm 0.02$ \\
\hline $\mathrm{BMI}, \mathrm{Kg} / \mathrm{m} 2( \pm \mathrm{SD})$ & $28.1 \pm 3.6$ \\
\hline
\end{tabular}




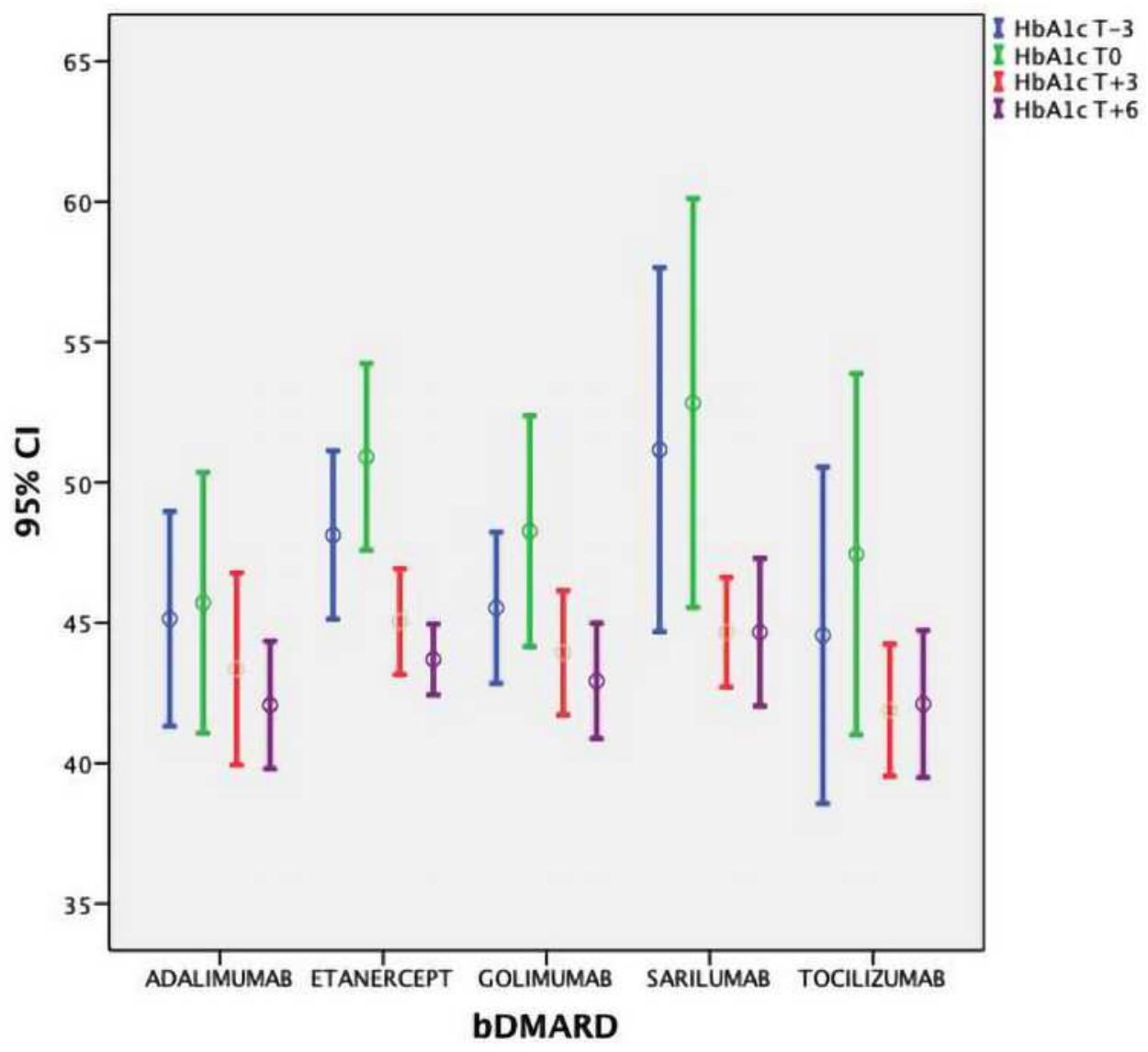

Figure I DAS28-CRP values during the study from 3 months before to 6 months after the start of therapy with bDMARDs.

\section{Discussion}

Rheumatoid arthritis is characterized by an increased cardiovascular risk comparable to that posed by type 2 diabetes mellitus. ${ }^{11,12}$ This attribute can be explained as a combination of traditional risk factors, such as hypertension and dyslipidemia, with the inflammatory milieu present in RA uncontrolled by drugs. ${ }^{10,13,14}$

The importance of recognizing and managing cardiovascular disease risk in RA patients was emphasized in the European League Against Rheumatism (EULAR) 2010 recommendations. ${ }^{15}$

In this preliminary study, we showed that treatment of active RA using a bDMARD improves concomitant 2TDM. The observed improvement was not due to a significant loss of weight or BMI variation (stable at each timepoint, T-3, T0, $\mathrm{T} 3$ and $\mathrm{T} 6, \mathrm{p}>0.5$ ) nor to a reduction in steroid doses; rather, it was the result of a lowering in inflammation, as demonstrated by decreased CRP and ESR values. Overall, the findings support the hypothesis that systemic inflammation as observed in active RA promotes insulin resistance; support efforts to prevent diabetes through optimal control of disease activity; and are intriguing regarding the role of each cytokine in determining the risk of developing diabetes.

Preclinical evidence can help us to hypothesize about the possible mechanisms behind this novel effect of bDMARDs. Immune cells, in particular macrophages and $\mathrm{T}$ cells, are nowadays recognized as important players in the pathogenesis of adipose tissue inflammation and, consequently, 2TDM. ${ }^{16}$

Fujii et al recently demonstrated that abatacept improved insulin resistance in a mouse model of dietinduced obesity, mainly through polarization of adipose tissue macrophages from the pro-inflammatory M1 to the anti-inflammatory M2 phenotype. ${ }^{17}$ IL-6 was also demonstrated to be independently associated with incident diabetes, as has been shown in other populations. ${ }^{18,19}$ It has been suggested that IL-6 is involved in the development of obesity-related and T2DM-related insulin resistance. Experimental and clinical studies now converge to show that several ILs, and primarily IL6, contribute to the 


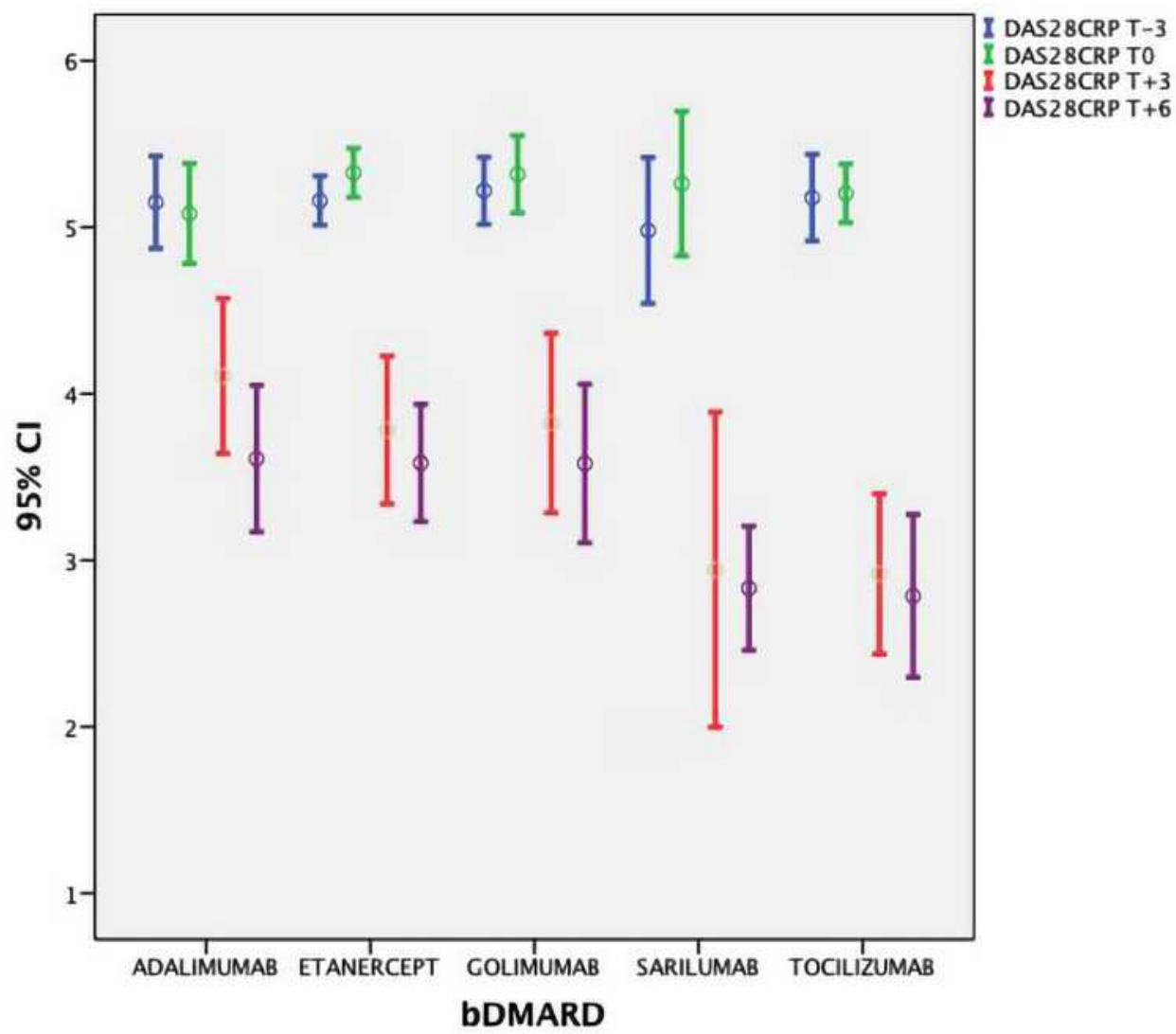

Figure $2 \mathrm{HbAlc}$ values during the study from 3 months before to 6 months after the start of therapy with bDMARDs.

pathology and physiology of T2DM through their interaction with insulin signaling pathways and beta-cell function. ${ }^{20,21}$

In our study, the use of anti-IL6 drugs (tocilizumab and sarilumab) has been shown to lead to a further improvement in glycated hemoglobin values compared to the use of other classes of bDMARD. However, the small size of the sample in question prevents us from reaching definitive conclusions $(\mathrm{p}=0.047$ ). Further study with longitudinal IL-6 measurement is needed in order to determine if IL- 6 is in the causal pathway

Table 2 Data on DAS28CRP, HbAlc and BMI for Each bDMARD Used, During All Observation Periods

\begin{tabular}{|c|c|c|c|c|c|c|c|c|c|c|}
\hline & \multicolumn{10}{|c|}{ bDMARD } \\
\hline & \multicolumn{2}{|c|}{ Adalimumab } & \multicolumn{2}{|c|}{ Etanercept } & \multicolumn{2}{|c|}{ Golimumab } & \multicolumn{2}{|c|}{ Sarilumab } & \multicolumn{2}{|c|}{ Tocilizumab } \\
\hline & Mean & SD & Mean & SD & Mean & SD & Mean & SD & Mean & SD \\
\hline DAS28CRP T-3 & 5.15 & 0.48 & 5.16 & 0.34 & 5.22 & 0.36 & 4.98 & 0.42 & 5.18 & 0.34 \\
\hline DAS28CRP T0 & 5.08 & 0.52 & 5.33 & 0.34 & 5.32 & 0.42 & 5.26 & 0.41 & 5.20 & 0.23 \\
\hline DAS28CRP $T+3$ & 4.11 & 0.81 & 3.78 & 1.03 & 3.82 & 0.97 & 2.94 & 0.90 & 2.92 & 0.63 \\
\hline DAS28CRP T+6 & 3.61 & 0.76 & 3.58 & 0.81 & 3.58 & 0.86 & 2.83 & 0.35 & 2.79 & 0.64 \\
\hline HbAlc T-3 & 45.1 & 6.6 & 48.1 & 6.9 & 45.5 & 4.9 & 51.2 & 6.2 & 44.6 & 7.8 \\
\hline HbAlc T0 & 46 & 8 & 51 & 8 & 48 & 7 & 53 & 7 & 47 & 8 \\
\hline $\mathrm{HbAlc} \mathrm{T+3}$ & 43 & 6 & 45 & 4 & 44 & 4 & 45 & 2 & 42 & 3 \\
\hline $\mathrm{HbAlc} \mathrm{T+6}$ & 42 & 4 & 44 & 3 & 43 & 4 & 45 & 3 & 42 & 3 \\
\hline BMI T-3 & 27.69 & 1.21 & 27.82 & 1.43 & 27.85 & 1.29 & 28.55 & 1.42 & 28.14 & 0.86 \\
\hline BMI TO & 29.33 & 1.33 & 28.30 & 1.35 & 28.52 & 1.33 & 29.39 & 1.29 & 28.70 & 1.17 \\
\hline $\mathrm{BMI} \mathrm{T}+3$ & 28.44 & 1.45 & 27.52 & 1.29 & 27.89 & 1.44 & 28.01 & 1.45 & 28.57 & 1.27 \\
\hline $\mathrm{BMI} \mathrm{T}+6$ & 28.00 & 0.99 & 28.26 & 1.05 & 28.68 & I.II & 27.99 & 0.85 & 28.92 & 1.03 \\
\hline
\end{tabular}


leading from obesity to diabetes. It therefore remains unknown whether blocking IL-6 might prevent the onset of DM in the general population and in patients with RA. In conclusion, our study, although with evident limitations (observational design, low number of patients, lack of a control group), provides preliminary evidence of a potential insulin-sensitizing effect of bDMARDs resulting from an anti-inflammatory effect, demonstrated by the significant reduction in the values of acute phase reactants. Obviously, our data need to be confirmed by more rigorous studies, including a control group, and at least direct measurements of insulin sensitivity. Our finding, if confirmed, could improve the management of comorbidity in RA patients. Cardiometabolic risk management, according to the EULAR recommendations, should be one of the biggest focuses for clinicians dealing with RA patients because greater disease activity in RA is associated with a greater risk of diabetes.

\section{Article Summary Strengths}

1. Patients with rheumatoid arthritis often present with diabetes mellitus. The present study evaluates the effect of rheumatological therapies on the progress of diabetes.

2. The data collected show an improvement in diabetes resulting from effective treatment of rheumatoid arthritis.

\section{Limitations}

1. The sample size is very small and the observation period is limited. This led to not being able to assess the possible differences between the various treatments used.

\section{Key Messages}

1. Diabetes mellitus and rheumatoid arthritis increase cardiovascular risk.

2. High levels of pro-inflammatory cytokines, as in uncontrolled rheumatoid arthritis, are correlated with poorer glucose balance in diabetes.

3. Better control of arthritis leads to better control of concomitant diabetes.

\section{Patient and Public Involvement}

Not applicable. It was not appropriate or possible to involve patients or the public in the design, or conduct, or reporting, or dissemination plans of our research.

\section{Data Sharing Statement}

Data are available upon request as Spss files or Excel files.

\section{Author Contributions}

All authors made a significant contribution to the work reported, whether that is in the conception, study design, execution, acquisition of data, analysis and interpretation, or in all these areas; took part in drafting, revising or critically reviewing the article; gave final approval of the version to be published; have agreed on the journal to which the article has been submitted; and agree to be accountable for all aspects of the work.

\section{Funding}

This study received no funding.

\section{Disclosure}

None of the authors have relevant conflicts of interest.

\section{References}

1. Solomon DH, Love TJ, Canning C, et al. Risk of diabetes among patients with rheumatoid arthritis, psoriatic arthritis and psoriasis. Ann Rheum Dis. 2010;69:2114-2117. doi:10.1136/ard.2009.125476

2. Jin Y, Chen SK, Liu J, et al. Risk of incident type 2 diabetes mellitus among patients with rheumatoid arthritis: a population-based cohort study. Arthritis Care Res. 2020;72:1248-1256. doi:10.1002/acr.24343

3. Jiang P, Li H, Li X. Diabetes mellitus risk factors in rheumatoid arthritis: a systematic review and meta-analysis. Clin Exp Rheumatol. 2015;33:115-121.

4. Nicolau J, Lequerré $\mathrm{T}$, Bacquet $\mathrm{H}$, et al. Rheumatoid arthritis, insulin resistance, and diabetes. Joint Bone Spine. 2017;84:411-416. doi:10.1016/j.jbspin.2016.09.001

5. Emamifar A, Levin K, Jensen Hansen IM. Patients with newly diagnosed rheumatoid arthritis are at increased risk of diabetes mellitus: an observational cohort study. Acta Reumatol Port. 2017;42:310-317.

6. Solomon DH, Reed GW, Kremer JM, et al. Disease activity in rheumatoid arthritis and the risk of cardiovascular events. Arthritis Rheumatol. 2015;67:1449-1455. doi:10.1002/art.39098

7. Esser N, Legrand-Poels S, Piette J, et al. Inflammation as a link between obesity, metabolic syndrome and type 2 diabetes. Diabetes Res Clin Pract. 2014;105:141-150. doi:10.1016/j.diabres.2014.04.006

8. Wu H, Ballantyne CM. Skeletal muscle inflammation and insulin resistance in obesity. J Clin Invest. 2017;127:43-54. doi:10.1172/JCI88880

9. Solomon DH, Massarotti E, Garg R, et al. Association between disease-modifying antirheumatic drugs and diabetes risk in patients with rheumatoid arthritis and psoriasis. JAMA. 2011;305:2525-2531. doi:10.1001/jama.2011.878

10. Lillegraven S, Greenberg JD, Reed GW, et al. Immunosuppressive treatment and the risk of diabetes in rheumatoid arthritis. PLoS One. 2019;14(1):e0210459. doi:10.1371/journal.pone.0210459

11. Avina-Zubieta JA, Thomas J, Sadatsafavi M, et al. Risk of incident cardiovascular events in patients with rheumatoid arthritis: a meta-analysis of observational studies. Ann Rheum Dis. 2012;71:1524-1529. doi:10.1136/annrheumdis-2011-200726

12. Peters MJ, van Halm VP, Voskuyl AE, et al. Does rheumatoid arthritis equal diabetes mellitus as an independent risk factor for cardiovascular disease? A prospective study. Arthritis Rheum. 2009;61:1571-1579. doi:10.1002/art.24836 
13. van Halm VP, Peters MJ, Voskuyl AE, et al. Rheumatoid arthritis versus diabetes as a risk factor for cardiovascular disease: a crosssectional study, the CARRE Investigation. Ann Rheum Dis. 2009;68:1395-1400. doi:10.1136/ard.2008.094151

14. Innala L, Moller B, Ljung L, et al. Cardiovascular events in early RA are a result of inflammatory burden and traditional risk factors: a five year prospective study. Arthritis Res Ther. 2011;13:R131. doi:10.1186/ar3442

15. Peters MJ, Symmons DP, McCarey D, et al. EULAR evidence-based recommendations for cardiovascular risk management in patients with rheumatoid arthritis and other forms of inflammatory arthritis. Ann Rheum Dis. 2010;69:325-331. doi:10.1136/ard.2009.113696

16. Lee BC, Lee J. Cellular and molecular players in adipose tissue inflammation in the development of obesity-induced insulin resistance. Biochim Biophys Acta. 2014;1842:446-462. doi:10.1016/ j.bbadis.2013.05.017

17. Fujii M, Inoguchi T, Batchuluun B, et al. CTLA-4Ig immunotherapy of obesity-induced insulin resistance by manipulation of macrophage polarization in adipose tissues. Biochem Biophys Res Commun. 2013;438:103-109. doi:10.1016/j.bbrc.2013.07.034
18. Liu C, Feng X, Li Q, et al. Adiponectin, TNF- $\alpha$ and inflammatory cytokines and risk of type 2 diabetes: a systematic review and metaanalysis. Cytokine. 2016;86:100-109. doi:10.1016/j.cyto.2016.06.028

19. Park HS, Park JY, Yu R. Relationship of obesity and visceral adiposity with serum concentrations of CRP, TNF-alpha and IL-6. Diabetes Res Clin Pract. 2005;69:29-35. doi:10.1016/j. diabres.2004.11.007

20. Fève B, Bastard JP. The role of interleukins in insulin resistance and type 2 diabetes mellitus. Nat Rev Endocrinol. 2009;5:305-311. doi:10.1038/nrendo.2009.62

21. Bastard JP, Maachi M, Lagathu C, et al. Recent advances in the relationship between obesity, inflammation, and insulin resistance. Eur Cytokine Netw. 2006;17(1):4-12.
Open Access Rheumatology: Research and Reviews

\section{Publish your work in this journal}

Open Access Rheumatology Research and Reviews is an international, peer-reviewed, open access journal publishing original research, reports, editorials, reviews and commentaries on all aspects of clinical and experimental rheumatology in the clinic and laboratory including the following topics: Pathology, pathophysiology of rheumatological diseases; Investigation, treatment and management

\section{Dovepress}

of rheumatological diseases; Clinical trials and novel pharmacological approaches for the treatment of rheumatological disorders. The manuscript management system is completely online and includes a very quick and fair peer-review system, which is all easy to use. Visit http://www.dovepress.com/testimonials.php to read real quotes from published authors. 